\title{
The needs of relatives of patients admitted to Italian critical care units: a survey comparing relatives' and nurses' perceptions
}

Fabrizio Moggia, RN, Nursing Teacher/Manager, School of Nursing, San Martino University Hospital, Genoa, Italy. * Stefano Biagi, RN, Nursing Teacher/Manager, Intensive Care Unit, Villa Scassi Hospital, Genoa, Italy. Viviana Pompei, RN, Nursing Teacher/Manager, Paediatric Neurosurgery Unit, G. Gaslini University Children's Hospital, Genoa, Italy.

E-mail: fmoggia@aniarti.it

Key words: critical care $*$ intensive care needs $*$ nurses $*$ relationship $*$ relatives

\section{SUMMARY \\ * This article presents the findings of a study that analysed the needs of relatives of patients admitted to Italian critical care units. \\ * Data were collected using a 31-item questionnaire adapted from the Critical Care Family Needs Inventory (Molter \& Leske, 1983). \\ * The questionnaire was completed by relatives of critical care unit patients and nurses between 24 and 72 hours after admission of the patient. \\ * A sample of 270 relatives and 290 nurses was gained from 43 critical care units in 22 hospitals. \\ * The needs most frequently indicated by relatives were for more information and support. Nurses also considered the need for information to be a priority. \\ * Relatives and nurses held similar views about the needs of patients. \\ * Nurses' perceptions of patients' needs was not influenced by either their age or experience.}

\section{INTRODUCTION}

In many studies the experience of having a relative admitted to an intensive care unit (ICU) is described as very stressful (Titler et al., 1991; Rukholm et al., 1991; Magotti et al., 1999). The emotions most frequently faced by the relatives are fear, anger, uncertainty with respect to what happened and what will happen, and a sense of guilt and frustration (Titler et al., 1991). The nurse is a central focus for supporting the relationship between a critically ill patient and their relatives. In fulfilling this role, the nurse organises and facilitates relatives' visits, coordinates caring interventions so that visits are not overly disturbed, develops a trusting and open relationship with both the patient and relatives, provides information about the plan of care and its organisation, and explains and reinforces information provided by medical staff. Developing a relationship with the relatives is not always easy - sometimes it is difficult to understand what their needs are and to manage their fear and anxiety appropriately.

This article presents the results of a descriptive survey which identified the needs of the relatives of patients admitted to a critical care unit environment. The results are compared with a description of the needs of relatives as perceived by the nurses. It presents the work of a group of Italian nurses who are all members of the Italian National Association of Critical Care Area Nurses (ANIARTI).

\section{RESEARCH DESIGN}

The study used a descriptive approach and replicates a survey previously undertaken in Trentino, a small region of Italy (Magotti et al., 1999). Previous studies in this field have used the Critical Care Family Needs Inventory (CCFNI) as a data collection tool. This tool was developed through the work of Molter in 1979 and Leske in 1986. Molter (1979) conducted a major study and identified a list of 45 need statements. Leske (1986) replicated Molter's work and the 45 need statements were randomly ordered and formed the first edition of the CCFNI. Relatives are asked to evaluate the level of importance of each of these 45 items, and to indicate the most important three. The items refer to different categories of need, for example the need for visiting times, the need for psychological support and reassurance, the need for information and the need for comfort. The instrument has been validated and used in many studies, in different contexts and translated into several languages, for example French (Coutu-Wakulczyk et al., 1990) and Dutch (Bijttebier et al., 2000).

\section{METHODOLOGY}

The survey was conducted over a two-year period and a total of 560 questionnaires were returned, of which 270 were completed by relatives and 290 by nurses. The sample of relatives was drawn from 43 critical care units in 22 hospitals. The units were either adult or paediatric intensive care units or coronary care units. The sample of nurses was drawn from the same units with the inclusion criterion that nurses had to have worked in the area for a minimum of six months prior to completing the questionnaire.

The survey instrument was based on the CCFNI with slight modifications for use in Italy. The number of items was reduced from 45 to 31 , and the questionnaire was changed to simplify the terminology. This modified tool was first used by Magotti et al. (1999).

Data were collected using three different questionnaires:

* One questionnaire for the relatives;

* One questionnaire for the nurses; 
* One questionnaire which provided data about the unit. The questionnaires were completed by a minimum of 20 relatives from each unit, with no more than one relative for each eligible patient. The relatives of patients who had been admitted for not less than 24 hours and for no more than 72 hours were included. They were asked to identify the 10 most important needs from the list of 31, and from these, to indicate the three they considered to be most important. The nurses were asked to indicate which were, in their opinion, the most important needs perceived as priorities by the relatives from the same list given to the relatives.

\section{RESULTS AND DISCUSSION}

The relationship of the relative to the patient were $44 \%$ spouse, $20 \%$ parent, $20 \%$ other and $16 \%$ siblings (see Figure 1 ).

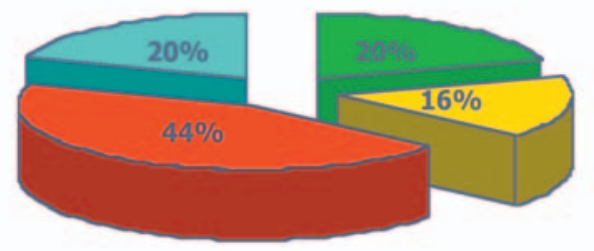

\begin{tabular}{|l|}
\hline Parent $\quad \square$ Brother/sister \\
$\square$ Wife/husband $\square$ Other
\end{tabular}

Figure 1. Relationship of the respondent to the patient.

A third (33\%) of the relatives was over 60 years of age, equally distributed between spouses and siblings. This equates with the age of patients in that $37 \%$ of them were over 70 years old, with a median age of 76 years. The admission to a critical care unit was unexpected in $57 \%$ of cases, while for the remaining $43 \%$ it was considered to be the consequence of the worsening of a pre-existing illness.

In all, $42 \%$ of relatives considered their family member (the patient) to be in a 'serious' condition, $45 \%$ thought the patient was getting better, while the remaining $13 \%$ were unable to evaluate the condition of the patient because they 'did not receive enough information'. This finding will be examined later in the analysis of the satisfaction of needs as perceived by nurses.

Of the nurses responding to the study, $65 \%$ were female, and $55 \%$ of the sample was aged between 30 to 40 years. In terms of critical care experience, $51 \%$ had more than six years' experience, $32 \%$ had between two and six years' experience, with the remaining $17 \%$ having had less than two years' experience. The median length of experience was 11 years. This demographic is unsurprising and can be explained by the relatively low turnover rate of personnel in Italian critical care units.

\section{Needs of relatives}

Table 1 identifies the top 10 needs as identified by relatives. It indicates the percentage of relatives identifying the need and its priority.

These results indicate that relatives have a clear need for information about patients, their condition and the treatment and care they are receiving.

Table 2 identifies the top 10 needs of relatives as perceived by nurses. In comparing Tables 1 and 2, it is pleasing to note the similar emphasis on information. This demonstrates concordance between relatives and nurses in terms of their perception of need.

\begin{tabular}{|c|c|c|}
\hline Needs & $\%$ & Priority \\
\hline To speak with the doctor at least once a day & 85 & 157 \\
\hline To know what is being done and why & 81 & 168 \\
\hline To be assured that the best possible care is given & 78 & 105 \\
\hline To be sure of being called at home if something positive occurs & 78 & 68 \\
\hline To get information in understandable terms & 61 & 57 \\
\hline To see that the patient is quiet and being cared for & 59 & 40 \\
\hline To have someone of reference in the hospital who can be called in order to receive information & 55 & 40 \\
\hline To feel that the staff at the hospital are taking care of your situation & 49 & 28 \\
\hline To know what the prognosis is & 46 & 34 \\
\hline To know exactly what is improving with the patient & 36 & 11 \\
\hline
\end{tabular}

Table 1. The needs of relatives.

\begin{tabular}{|c|c|c|}
\hline Needs & $\%$ & Priority \\
\hline To get information in understandable terms & 84 & 110 \\
\hline To know what is being done and why & 83 & 152 \\
\hline To speak with the doctor at least once a day & 81 & 106 \\
\hline To be assured that the best possible care is given & 76 & 111 \\
\hline To be sure of being called at home if something positive occurs & 65 & 30 \\
\hline To see that the patient is quiet and being cared for & 60 & 50 \\
\hline To have a waiting room nearby and comfortable & 52 & 21 \\
\hline $\begin{array}{l}\text { To receive explanations about devices and instrumentation connected to the patient before entering the } \\
\text { ICU }\end{array}$ & 41 & 12 \\
\hline To know what the prognosis is & 39 & 25 \\
\hline To feel that the staff at the hospital are taking care of your situation & 34 & 21 \\
\hline
\end{tabular}

Table 2. The needs of relatives as perceived by nurses. 
Table 3 identifies the needs considered as being less important by relatives and nurses. Again, there is a strong similarity between the two groups. The largest difference relates to the need 'To have expert personnel as reference for family problems'. This may be more reflective of the nurses' needs which they then transfer or interpret as relatives' needs.

The priorities of relatives' needs in different subgroups of patients (younger and older) were also identified. Table 4 shows the results of a subgroup analysis of the questionnaires completed by relatives of patients aged between 0-15 years. The median age of the patients in this sample was six years $(n=17)$. The need statements reflect those of the larger sample but the need 'To know what is being done and why' was ranked as the most important by all. It is difficult to draw any inferences from this finding as the sample size is relatively small.

The questionnaires from 107 relatives of older patients were included in this analysis. The findings (Table 5) demonstrate the similarities in this subgroup with others. The relatives expressed as their priority the need 'To speak with the doctor at least once a day'. The age of the respondents in this subgroup was between 40 to 50 years and they were mainly sons or daughters of the patient. As a result of their previous experiences, they may have a perception of the health service as being medically dominated and may not understand fully the role of nurses in these critical care areas.

Data were also analysed from relatives of patients who were considered to be seriously ill and those that were considered to be improving. Once again, the findings in both groups showed distinct similarities.

While having some slight differences in priority ranking, overall it is interesting to note that the variables of age and severity of illness do not appear to influence the needs identified by relatives.

\section{Nurses' perceptions}

The data collected from nurses were analysed in three groups according to their length of experience in critical care. Of the 46 nurses who had less than two years' experience in critical care, the first three priority needs they identified were the same as those identified by relatives. Of the 85 nurses who had been working in critical care for between two to six years, $90 \%$ identified the need 'To know what is being done and why' as the highest priority. The most experienced nurses, those with over six years' experience

\begin{tabular}{|l|l|l|}
\hline Needs & $\begin{array}{l}\text { \% indication } \\
\text { of relatives }\end{array}$ & $\begin{array}{l}\text { \% indication } \\
\text { of nurses }\end{array}$ \\
\hline To have a place where to be alone & 2 & 2 \\
To be allowed to have access to the restaurant of the hospital & 3 & 5 \\
To have expert personnel as reference for family problems & 3 & 11 \\
To have information about the qualifications of the personnel that take care of the patient & 12 & 8 \\
\hline
\end{tabular}

Table 3. Needs considered to be less important.

\begin{tabular}{|l|l|l|}
\hline Needs & $\mathbf{n}$ & $\mathbf{\%}$ \\
\hline To know what is being done and why & 17 & 100 \\
To speak with the doctor at least once a day & 15 & 88 \\
To be sure of being called at home if something positive occurs & 14 & 82 \\
To be assured that the best possible care is given & 13 & 76 \\
To have someone of reference in the hospital who can be called in order to receive information & 11 & 64 \\
\hline
\end{tabular}

Table 4 . The needs of relatives of patients aged 0-15 years.

\begin{tabular}{|l|l|l|}
\hline Needs & n & \% \\
\hline To speak with the doctor at least once a day & 94 & 87 \\
To be sure of being called at home if something positive occurs & 90 & 84 \\
To know what is being done and why & 86 & 80 \\
To be assured that the best possible care is given & 84 & 78 \\
To get information in understandable terms & 68 & 63 \\
\hline
\end{tabular}

Table 5. The needs of relatives of 'older' patients.

\begin{tabular}{|c|c|c|c|c|}
\hline \multirow[t]{2}{*}{ Needs } & \multicolumn{4}{|c|}{ Length of experience } \\
\hline & $<2$ years & $2-6$ years $>$ & 6 years & Total \\
\hline To have a waiting room nearby and comfortable & $12 / 20$ & $31 / 42$ & $61 / 76$ & $104 / 138$ \\
\hline $\begin{array}{l}\text { To have flexible visiting times according to the needs of the } \\
\text { family }\end{array}$ & $11 / 16$ & $18 / 28$ & $23 / 34$ & $52 / 58$ \\
\hline $\begin{array}{l}\text { To receive explanations about devices and instrumentation } \\
\text { connected to the patient before entering the ICU }\end{array}$ & $11 / 19$ & $22 / 41$ & $29 / 51$ & $62 / 111$ \\
\hline
\end{tabular}

Table 6. Needs ranked differently by nurses and relatives. 
$(n=133)$, indicated the priority need as 'To get information in understandable terms'.

There were several needs that were ranked differently by nurses and relatives (see Table 6). The need 'To have a waiting room nearby and comfortable' was ranked more highly by nurses, especially those with longer experience, whereas only 96/291 relatives considered it to be a priority. This finding may be related to the relative importance of needs. For example, the need to have information about the condition of the patient was felt by relatives to be a priority. When a patient is critical, this may be perceived by the relative as being far more important than their own comfort.

Further analysis of the data showed that the need 'To get information in understandable terms' was perceived as being received with a satisfactory response from relatives by only $32 \%$ of the nurses. The need 'To receive explanations about devices and instrumentation connected to the patient before entering the ICU' was perceived as receiving an unsatisfactory response by relatives, mainly by newly employed nurses but also by some with more years of experience. This is probably due to the non-expert nurses finding it more difficult to give appropriate technical explanations to the relatives.

\section{CONCLUSIONS}

This study demonstrates that, for the most part, nurses' perceptions of the needs of relatives of patients in critical care units are similar to the perceptions of the relatives themselves. The age and length of experience of nurses does not influence their perceptions. It is evident that both nurses and relatives consider the need to receive information to be very important. However, it is interesting that only $32 \%$ of nurses considered the information given to the rela- tives to be satisfactory. It is recommended that further research is undertaken to investigate relatives' views of the quality of information they receive from health care personnel.

\section{ACKNOWLEDGEMENT}

The authors would like to acknowledge the research support given by P. Di Giulio.

\section{REFERENCES}

Bijttebier P, Delva D, Vanoost S, Bobbaers H, Lauwers P \& Vertommen H. (2000) Reliability and validity of the Critical Care Family Needs Inventory in a Dutch-speaking Belgian sample. Heart \& Lung 29 (4), 278-286.

Coutu-Wakulczyk G \& Chartier L. (1990) French validation of the Critical Care Family Needs Inventory. Heart \& Lung 19 (2), 192-196.

Leske JS. (1986) Needs of relatives of critically ill patients: a follow-up. Heart \& Lung 15 (2), 189-193.

Magotti A, Saiani L \& Drigo ML. (1999) The needs of relatives of patients admitted to intensive care units in the Trentino region. Assistenza Infermieristica e Ricerca:Air. 18 (3), 124-130.

Molter NC. (1979) Needs of relatives of critically ill patients: a descriptive study. Heart \& Lung 8 (2), 332-339.

Molter NC \& Leske JS. (1983) Critical Care Family Needs Inventory. Milwaukee: Jane S. Leske, School of Nursing, University of Wisconsin.

Rukholm E, Bailey P, Coutu-Wakulczyk G \& Bailey WB. (1991) Needs and anxiety levels in relatives of intensive care unit patients. Journal of Advanced Nursing 16 (8), 920-928.

Titler MG, Cohen MZ \& Craft MJ. (1991) Impact of adult critical care hospitalization: perception of patients, spouses, children and nurses. Heart \& Lung 20 (2), 174-182. 